\title{
MANAJEMEN PENGETAHUAN DAN MODAL SOSIAL DALAM PENGEMBANGAN SUMBER DAYA MANUSIA
}

\author{
Ahmad Muhammad Diponegoro \\ Universitas Gad/ah Mada
}

\begin{abstract}
The purpose of this study is to compare two current western theories of knowledge management that was written by Senge and Nonaka and social capital management with islam. It was belleved. That those theories were very important to overcome the crisis that hit some countries. The result was islam has theories that equally well compare to western, doesn't out of date. and still applicable in modern sociery.

Kata kunci : managemen pengetahuan, modal sosial, dan pengembangan sumberdaya manusia.
\end{abstract}

Ahmad Muhammad Diponegoro adalah kandidat doktor Psikologi di Fakultas Psikologi Universitas Gadjan Mada Yogyakarta.

\section{PENDAHULUAN}

D ewasa ini, organisasi beroperasi dalam suatu lingkungan yang sarat dengan perubahan, turbulensi, dan ketidakpastian. Perubahan yang terjadi juga berbeda bila dibandingkan dengan era sebelumnya, balk dalam arah dan pola, maupun magnitude-nya. Akibatnya, organisasi tidak dapat mengandalkan pada jenis tindakan terencana yang disusun berdasarkan asumsi yang lama. Terkait dengan konstelasi ini, pengembangan organisasi yang selama int ditempuh tidak lagi dapat menjadi keberhasilan dan kelangsungan hidup organisasi. Turbulensi dan krisis manajemen nampaknya juga sedang menerpa keras terhadap berbagal perusahaan d indonesia. Menurut penulis, ada beberapa hail penting untuk dlbicarakan dalam pembenahan manajemen sumber daya di Indonesia. Hal ini karena adanya berbagai paradigma baru yang 
menggeser paradigma lama (Ancok, 1995). Paradigma bisnis baru ini antara lain toleransi terhadap ambiguitas, manajemen proaktif, saling ketergantungan antar korporat, integrasi vitual, penekanan pada lingkungan kompetitit, dan kesinambungan inovasi baru, serta berupaya menciptakan pasar masa depan, perubahan yang tidak berkesinambungan, percepatan dan responsif, kepemimpinan dari setiap orang, keluwesan yang permanen, kendali melalui visi dan misi, pembagian informasi, serta kreativitas dan inovasi (Ancok, 1999).

Semua perusahaan ingin tetap survive, berumur panjang, bahkan terus jaya. Pada kenyataannya, tenyata lebih banyak perusahaan rubuh dan tidak bangun lagi. Telah diidentifikasi adanya dua aspek yang menyebabkan mengapa suatu organisasi bisnis gagal bersaing. Pertama, banyakorganisasi yang gagal untuk ke luar dari lingkungan mas a lampau (escape from the past) yakni kemampuan meninggalkan paradigma lama dalam menyiasati strategi blsnis saat ini. Kedua, banyak organisasi yang gagal pula untuk menerawang masa de pan (invent the future), dengan proses pembelajaran koiektif. Untuk indonesia, menurut pengamatan beberapa ahli, masalah modal sosial (social capital) pun merupakan hal yang perlu dibenahi, sebab keruntuhan berbagai jenis perusahaan yang mengikuti runtuhnya rezim orde baru nampaknya tidak dapat lepas dari rapuhrya modal sosial yang ada di Indonesia. Banyak perusahaan dan pengusaha seolah tercoreng habis di pentas internasional. Padahal sebelumnya pengusaha Indonesia memiliki nama global dengan kemampuan yang luar biasa. Beberapa orang Indonesia untuk beberapa tahun selalu muncul dalam deretanorang terkaya di dunla. Pada masa itu, tak ada pihak luar yang ragu-ragu menyerahkan uangnya untuk diputar di Indonesia. Setelah terjadi krisis, kepercayaan mitra Indonesia sedikit demi sedikit luntur. Mereka kini nampak, menuntut etika dan profesionalitas pengusaha Indonesia, bahkan letter of credit dari bank sentral pun tak dihargai. Nama baik negara sirna.

Tulisan ini akan membicarakan masalah pengetahuan dan modal soslal yang di dalamnya mengandung masalah etika. Menurut penulis, hal ini sangat erat berkaitan dengan jalan keluar dari krisis serta kaitannya dengan berbagai paradigma baru. Pembahasan pertama akan dimulai dengan pembahasan pengetahuan dan berbagai hal yang berkaitan dengan pengembangan manajemen sumberdaya manusia.

\section{PENGET AHUAN}

Untuk memperoleh pengetahuan orang harus belajar. Belajar merupakan strategi beradaptasi dalam perubahan. Krisis seberat apa pun sebenarnya blsa diatasi kalau mau beradaptasi dan jeli menyiasati perubahan. Sikap memaksakan paradigma lama, yang sudah nyata-nyata bertentangan dengan tuntutan realitas, hanya akan membuat hancur perusahaan atau ditinggalkan. Manusia perlu belajar dan terus belajar untuk eksis dan memegang kendali. Tentunya selama zuntutan realitas ini tidak bertentangan dengan pedoman-pedoman rellgius yang diyakini. Dengan meningkatnya nllal strategis pengetahuan, pengetahuan merupakan kapital yang tak kalah pentlngnya dengan kapital yang berbentuk finansial.

Manusia adalah pencipta pengetahuan yang paling efektif, karena memiliki kemampuan membuat ide dari inspirasi. Ide yang diciptakan manusia merupakan koman dan yang mengerahkan sistem pengetahuan yang ada untuk membentuk nilal tambah produk.

Banyak pendekatan dlgunakan untuk menganalisis hakikat pengetahuan, proses pembentukannya serta strategi yang 
diperlukan untuk mengembangkan sebagai aset perusahaan. Di antaranya yang terkenal adalah konsep organisiasi belajar flearning organizationj oleh Senge, dan knowiedgecreating companyoleh Nonaka.

\section{Learning organization.}

Walaupun istilah "learning organization" sering diberi makna yang tidak seragam, tetapi bila dibedakan dengan "organizational learning"maka pebedaan antara keduanya dapat ditemukan dari pertanyaan yang dimuncukkan. Leaning organization merupakan jawaban dari pertanyaan: bagaimana seharusnya sebuah organisasi belajar - how should an onganization learn? Sementara onganizational learning menjawab pertanyaar: how does an organization learn (bagaimana suatu organisasi belajar?) (Tsang, 1997).

Dalam bukunya "The Fifth Discipline: The Art and Practice of the Learning Organization", Senge menolak anggapan bahwa organisasi dan berbagai peristiwa di dalamnya sebagal kekuatan-kekuatan yang berdiri sendiri. Menu rut Senge, organisasi adalah sebuah kesatuan yang padu, sehingga membutuhkan sebuah komitmen yang menyatu untuk mengoperasionalisasikannya secara efektif. Aktivitas belajar tidak hanya kewajiban pemimpin, tetapi juga kewajiban para karyawan. Hal ini sesuai dengan pergeseran paradigma kepemimpinan yang dahulu hanya dipegang oleh satu orang, tetapi sekarang masing-masing individu dalam organisasi harus bisa memimpin, sebagaimana regu arung jeram yang sedang mengarungi jeram yang berbahaya, di mana perahu tidak selalu berlayar dalam satu posisi, tetapi dengan segala bagian perahu dapat berada d bagian depan (Ancok, 2000).

Belajar, yang termasuk di dalamnya proses informasi (Makhija, et al., 1997) dapat dirumuskan sebagai aktivitas untuk meningkatkan pengertian dan kesadaran tentang diri sendiri (self-awareness), lingkungan (cosmo-awar eness), dan relasi (Bughan, et al. 1997; Ancok, 1996; Burton, 1995) ke tingkat yang lebih dalam dan tinggi, sehingga melalui ketajaman pengertian itu manusia dimungkinkan untuk hid up dengan harmoni, relevan, dan aktual dengan lingkungan (principle of relevance), mendayagunakan potensi realitas lingkungan untuk menciptakan nilai organik bagi lingkungan tersebut, sehingga memperoleh nllai tukar yang sepadan (principle innovatlon), dan meningkatkan secara kontinyu mutu nilai-nilai organik, yang diciptakan tadi, untuk memperbesar nilai tukar (principle of quality).

Menghadapi berbagai perubahan manajemen di barat (Thomas, 1997, Ali, etal 1996), Senge mengajukan lima disiplin yang menjadi komponen utama proses pembelajaran, yaitu personal mastery (pengendalian pribadi), mental models (model mental), membangun visi bersama, learning team (belajar sebagal tim) dan systemic thinking (berpikir sistemik).

\section{a. Pengendalian pribadi}

Pada dasarnya pengendalian adalah memahami sejelas-jelasnya segala hal yang betul-betul berarti dan membiarkannya menuntun hidup. Ini adalah landasan spiritual organisasi. Perusahaan yang menolak untuk mendorong pertumbuhan belajar karyawannya $a_{i}$ berartl sedang menyla-nylakan potensi sumber dayanya yang terbesar (Makhija, ef al 1997). Disiplin ini lebih membutuhkan sentuhan kecakapan (proficiciency) ketimbang kekuasaan (dominance). Drang yang berhasil memperoleh apa yang dinginkan umumnya adalah orang yang bukan cum a piawal secara profesional, tetapi juga cakap mengendalikan dirinya (Burton, et al., 1995). Pengendalian diri inl biasanya dimulai darl pembicaraan yang baik (Mc Millan et al, 1997). Di samping itu, ia selalu mempertegas tujuan dan meinfokuskan diri kepada 
tujuan, sambil terus mengembangkan kapasitas kegigihan dan objektivitasnya.

\section{b. Model mental}

Model mental berperan sebagai seperangkat asumsi dan gagasan yang menentukar cara manusia memandang dunia, sekaligus mempengaruhi perilaku mereka (Miltonsmsith, 1997; Draadt, 1997). Tetapi kebe radaan dan kekuatan pengaruhnya sering tidak disadari. Senge menyatakan bahwa model mental merupakan proses introspeksi untuk memahami asumsi, keyakinan, prasangka, dan lain-lain, yang dimunculkan ke permukaan agar dapat diuji secara kritis. Proses ini membutuhkan kemauan dan kemampuan untuk melakukan dialog pembelajaran yang seimbang, jelas rendah hati, dan dengan lapang dada mengakul keterbatasannya, serta siap menerima pencerahan untuk menjadi model mental baru melalui proses pembeiajaran (Pascale, et al 1981; Dean, 1997; Collin, 1997).

\section{c. Visi bersama}

Pemimpin yang luar biasa cerdasnya, tak akan mampu berbuat banyak bila perusahaan tidak mempunyai visi bersama. Perusahaan akan dapat rontok dalam sekejap. Disiplin ini mengajarkan bahwa kepatuhan semu tidaklah penting, tetapi yang terpenting adalah keinginan karyawan untuk maju bersama perusahaan (Ancok, 1999: Enderle, 1997). Dengan membangun visi bersama, karyawan dari semua level bisa menumbuhkan rasa memiliki dan tanggunglawab yang besar terhadap maju mundurnya perusahaan. Multipolar, IBM, Polaroid, dan Apple adalah contoh perusahaan yang menunjukkan penerapan visi bersama yang berhasil.

Visi bersama menuntur kemampuan dan keterampilan untuk menggali gambaran bersama tentang masa kinidan masadepan perusahaan yang dihayati sepenuh hati oleh seluruh anggota organisasi, sehingga mereka punya komitmen bersama untuk menjaga agar masa kini dan masa depan itu menguntungkan bagi semua (Cheng, et al, 1997; Zang, 1997; Vanbergeijk ot al, 1997). Jadi, mendikte visi yang tidak dihayati bersama, tidak akan menghasilkan produktivitas.

\section{d. Belajar sebagai tim}

Disiplin ini muncul dengan anggapan bahwa sebuah tim akan lebih efisien dan efektif dibanding individu yang bekerja secara terpisah, sebagaimana pernah diteiiti oleh Simonin (1997) dalam learning organisation. Tetapi, harus hati-hati, tim yang tidak fungsional justru akan menghasilkan kinerja yang jauth lebih buruk dan mahal dari hasil individu yang terburuk dan termahal. Bisa jadi sekelompok manajer cerdas dalam bekerja sama menghasikan produk yang sama dengan pekerjaan kolektif orang yang berkemampuan sangat rendah (Anand e al. 1998).

Agartim dapat memaksimalkan sumber daya yang mereka miliki, setiap individu yang bergabung bersedia melepaskan sentimen keindividuannya dengan betul-betul powersharing(Dovey, 1997), dan berusaha sebisa mungkin untuk meleburkan diri ke ide pemikiran kolektif (Simonin, 1997). Dalam tin harus ada komunikasi terbuka dan saling mempercayai (trust) sehingga tercapal tingkat penetrasi dan inovasi, yang tidak dapat dijangkau oleh para anggota secara individual (Colins, 1997). Salah satu cara adalah dengan membuat organisasi tanpa batas (Ancok, 2000b).

Belajar sebagal tim menentukan kelangsungan hidup organisasi (Dovey, 1997). Individu tidak bisa melakkukan fungsi belajar bagi organisasi organisasi pun tidak bisa belajar kaku tim dalam organisasi tak dapat belajar (Hansen, et al., 1999). 


\section{e. Berpikir sistemik}

Cara berpikir yang umum dipakai adalah berpikirparsial, melihat dan menilai sesuatu secara terpisah, dan bagian per bagian, sehingga akibatnya pemahaman yang didapat pun sepotong-potong. Tidak utuh dan tidak menyeluruh. Tentu saja cara berpikir atau cara pandang seperti ini sering menimbulkan salah paham. Sebagai contoh, jika kelima disiplin dijalankan satu per satu, maka yang akan dicapai adalah kebingungan. Fetapi harus terpadu (Lim, 1995).

Kemampuan memilih (the power of choice) juga merupakan perangkat yang kita perlukan untuk memilih antara yang baik dan yang buruk, antara yang berguna dara yang merugikan, antara yang suci dan yang profan, bahkan antara yang baik dan lebih baik, atau antara yang buruk dan lebih buruk.

Menur ut Wick dan Leon (dalam Hansen et al., 1999), kebiasaan paling buruk dalam proses belajar adalah kebiasaan untuk menutupi kesalahan. Findakan ini hanya akan membuat kita kehilangan peluang untuk belajar. Tetapi mengakui kesalahan saja belum cukup, perlu langkah evaluatif untuk mengetahui d mana letak kesalahannya, faktor-faktor apa saja yang menyebabkan kesalahan itu terjadi, dan bagaimana seharusnya. Tindakan yang diambil supaya kesalahan serupa tidak terulang lagi, serta manfaat apa yang bisa diambil dari kesalahan tersebut. Hasil kesalahan tersebut kemudian disebarluaskan ke selunuh jajaran organisasi, sebagai materi pelajaran yang sangat berharga.

Wick dan Leon yakin, cara yang terhebat untuk belajar adalah dengan mempelajari orang, perusahaan, dan teknik-teknik lain, yang sudah terukti berhasil. Tentu saja proses mengamati ini harus dilakukan sekritis mungkin, tidak asal mengamati. Inilah yang disebut benchmarking.

Benchmarking adalah praktik mencari orang atau organisasi yang terbaik di bidang- nya untuk dipelajari (Cohen, et al.1997). Contoh klasik adalah Motorola yang membencmarkDomio's Pizza guna mencari tahu orang yang paling efektif untuk mengurangi waktu pengiriman telepon genggamnya ke pelanggan. Jadi yang diam bil dan dipelajari benar-benar keunggulan perusahaan yang d benchmark, terutama keunggulan yang memang dibutuhkan untuk meningkatkan kinerja, sehingga dalam proses mempelajari keunggulan pihak-pihak lain ini, perusahan yang di-benchmarktidak harus perusahaan besar yang namanya sudah sangat terkenal, sebab yang dibutuhkan hanyalah keunggulan-keunggulan tertentu yang tidak kita miliki.

Jadi akan nampak nanti, bahwa belajar merupakan syarat mutlak untuk mempertahankan eksistensi, sekaligus menjadi kunci untuk menaikkan kualitas diri dan organisasi, atau untuk mengambil maniaat dari krisis, berpindah ke paradigma yang baru, sehingga pihak-pihak yang melakukan aktivitas pembelajaran secara konsisten, intensif, evaluatif, dan komit, bisa dipastikan akan lebih unggul dibanding mereka yang tidak melakukannya (Ancok, 2000a).

\section{Organizational knowiedge creafion}

Felah banyak pembahasan teoretis yang mengupas keberhasilan perusahaan multinasional Jepang dalam mengembangkan usahanya dengan memenangkan kompetisi global dalam situasi yang penuh transisi inovasi tanpa henti. Organisasi bisnis yang baik adalah tidak hanya mampu sebagal proses pengetahuan, tetapi juga pencipta pengetahuan. Hasil penelitian terhadap perusahan-perusahaan Jepang. sementara ini menunjukkan bahwa know ledge creation telah menjadi sumber inovasi yang penting bag mereka dalam persaingan intemasional (Hauptman, et al, 1997; Chakarabarti, 1997; Rothberg, 1997). Perusahaan Jepang telah menjadi berhasil karena ke- 
ahlian dan pengalaman mereka dalam organizational knowiedge creation seperti Honda, Canon, Matsushita, Kao, atau Sharp yang berkembang menjadi perusahaan gobaldengan membuka banyak cabang industri d luar negara Jepang (Pascale, 1981).

Organizational knowledge creation beratti kemampuan perusahaan secara keseluruhan menciptakan pengetahuan baru, produk, pelayanan, dan sistem. Organizational knowledge creation adalah pembeda utama cara-cara berinovasi perusahaan Jepang. Inovasi yang terus menerus akan mengakibatkan keunggulan bersaing.

Meskipun menggunakan istilah "organizational knowledge creation" tetapi organisasi tidak dapat menciptakan pengetahuan pada dirinya tanpa inisiatif dari individu dan interaksi yang terjadi dalam kelompok. $\mathrm{Hal}$ ini sejalan dengan pendapat Clay Carrdalam bukunya "Choice, Chance and Organizational Change"yangmengemukakan: 'only individuals can decide to change and only individuals can actually change.'

Pengetahuan dapat dijelaskan atau dikristalisasikan pada level kelompok melalui dialog, diskusi, berbagi pengalaman, dan pengamatan. Jadi bukan satu departemen atau kelompok eksperimen yang secara eksperimen telah menciptakan pengetahuan baru, melainkan para karyawan-karyawan teknis, para manager dari berbagai tingkat, dan juga pelaku-pelaku dalam menciptakan pengetahuan baru tersebut, walaupun mereka mempunyai peran yang berbeda. Faikta menun jukkan, kreasi pengetahuan baru adalah hasil dari suatu interaksi yang dinamik di antara mereka. Jadi, Knowledge Creation berjalan secara multi level, artinya mekanisme interaksi pengetahuan tersebut berjalan dalam lingkup total organisasi dari lapis atas sampai dengan lapis bawah dalam mekanisme Top Down dan Eottom Up.

\section{KERANGKA TEORI ORGANIZATIONAL KNOWLEDGE CREATION}

Ikujiro Nonaka dalam bukunya "The Knowledge-Creating Company" (1995) mengemukakan bahwa pengembangan kerangka kerja teori, dilakukan dengan menjelaskan pada dua dimensi dimana konversi pengetahuan mengambil tempat antara pengetahuan tacit (mirip dengan ilham-bisa dimasukkan sebagal aset tak wujud atau intangible asset) dan pengetahuan eksplisit, (sebagal contoh pengetahuan tentang gravitasi (Pulos, 1997). Jadi Knowledge creating tersebut terjadi oleh adanya perpaduan antara ilmu pengetahuan tacit dengan explicit.

Tacit knowledge memiliki sifat sangat personal dan individual yang dipengaruhi oleh pengalaman kerja, bersifat intuitif, kepercayaan dirl, ditopang oleh nilai-nilai yang melekat, dan know-how. Sedangkan pengetahuan eksplisit adalah sebagaimana yang dikembangkan dari barat, yaitu empirisistik dan positifistik (Zack, 1999). Yang menjadi masalah kemudian, bagaimana membuat tacit knowledge terucapkan. Sebagai jalan keluar dibuat metode interview terhadap ahli tacit knowledge tertentu, sehingga jawaban jawaban yang terkumpul dikompilasi dalam suatu tulisan yang mudah dipahami (Garrigou et al, 1998). Jadl pengalaman saja tidaklah cukp untuk memperoleh keuntungan yang terbesar dari kolaborasi, pengalaman harus di internalisasi, dan know how kolaboratif harus dikembangkan untuk menyokong keuntungan kolaboratif masa depan (Simonin, 1997).

\section{THE HYPERTEXT ORGANIZATION}

Knowledge creation perlu ditopang déngan struktur organisasi yang tepat disebut sebagai hypertext organization. Dalam konteks knowledge creating, organisasi harus memiliki kapabilitas untuk meng- 
kondisikan terjadinya eksploitasi kapabilitas pegawai, dan akumulasi dalam sharing knowledge creating yang berlangsung secara terus menerus. Hypertext organization dibuat dalam hubungan antar lapisan atau konteks: the business system, the project teams, and the knowledge base. Sebagaimana terlihat pada gambar, lapisan sentral adalah lapisan business system yang tetap melakukan operasi-operasi futin sehingga struktur birokrasi cocok untuk melakukan efisiensi kerja yang rutin. Lapisan ini bentuknya seperti hirarki piramida biasa. Lapisan atas adalah lapisan projoct team, dl mana berbagai tim proyek terlibat dalam kegiatan-kegiatan knowledgecreating seperti pengembangan produk baru Anggotaanggota tim diambil dari sejumlah unit yang berbeda-beda. la berada dalam lapisan business system dan memberikan keleluasaan serta kewenangan penuh pada tim proyek sampai proyek selesai. Lapisan bawah adalah lapisan knowledge base, di mana organizational knowledge dibangkitkan di atas dua lapisan melalui rekategorisasi dan rekontekstualisasi. Lapisan ini (knowledge base) tidak nyata tampak seperti struktur organisasi yang sebenamya, tetapi terta nam dalam visi perusahaan, budaya organisasi atau teknologi. Visi perusahaan menyediakan secara langsung bagi pengembangan teknologi atau produk-produknya dan memperielas bidang-bidang yang ingin dikerjakannya. Pola pikir dan tindakan setiap pegawai berbudaya organisasi Asia Timur. Sementara visi perusahaan dan budaya organisasi menyediakan knowledge base untuk pembuka tacit knowledge, pembuka :eknologi, dan membangkitkan explicit knowledge pada dua lapisan lainnya (lapisan project team dan business system).

\section{Membuat knowledge networkdengan dunia luar}

Sebenarnya hal ini merupakan bukti bahwa pada masa ini, perusahaan pertu saling bergantung. Tidak semuanya dikerjakan sendirl sebagaimana dalam kasus Pertamina yang mengakibatkan perusahaan tersebut menjadi be ban (Anook, 1999), mestinya harus kerija sama dengan perusahaan lain yang umumnya yang berkecimpung dalam perhotelan dan sebagainya (Ancok. 2000a).

Keterbatasan pemikiran dan pengetahuan baru d antara individu-individu dalam perusahaan akan selalu muncul. Untuk itu dakam penerapan knowledge creation perlu dilakukan knowledge networkdengan dunia luar. Hal ini relevan dengan pendapat Leonard Barton (1995), bahwa aktivitas membangun pengetahuan perlu dímpor dari lingkungan eksternal. Sementara Joseph $L$ Dracco $J R_{1}$ dalam bukunya "The Knowledge Link" mengemukakan bahwa Rogers Smith dan John Akers, chairman of GM dan IBM tahun 1980-an, membuka suatu koridor kerjasama ilmu pengetahuan (knowledge links) yang bersifat komplektan dllaksanakan dalam berbagai jenis studi misainya studi outomobile dengan teknologi komputer, dalam wujud kegiatan disain, instalasi dan operasi komputer (Bradaracc, 1991). Sedangkan Huges Aircraft dan Generai Motor bekerjasama untuk kepentingan departemen pertahanan dengan istilah pengembangan Pentagon capitalism dalam wujud intelligence soltware product. Jadi perspektif pemlkiran baru perlu memperhatikan intensifikasi knowledge link dan product linkdalam usatu perspektif alians| kerjasama lintas negara (Bradaracc, 1991). 


\section{Knowledge cration: sebagai strategi resource-based}

Ada kecenderungan bahwa knowledge creation mereka merupakan suatu strategi resource-based, karena knowledge crination akan terus menerus menggali sumber daya potensial yang dimiliki suatu perusahaan untuk melahirkan inovasi yang berkelanjutan. sehingga tidak menutup kemungkinan bahwa perusahaan yang menerapkan knowledge creation akan mampu menciptakanproduk atau jasa yang belum ada di pasar atau belum ada dalam lingkungan industri ter. tentu. Hal ini memungkinkan perusahaan lebih mampu dalam persaingan masa depan karena persaingan masa depan lebih merupakan persaingan memperebutkan opportunity share daripada memperebutkan market share.

\section{MODAL SOSIAL.}

Paul Ormerod (1997), dengan sangat tepat mengatakan bahwa ilmu ekonomi akan mati kalau tidak lagi memperhatikan dan bersentuhan dengan nilai-nilai sosial budaya suatu masyarakat.

Pada level perusahaan, hal yang sama juga berlaku. Kemampuan suatu perusahaan untuk bertahan, khususnya di tengah badai krisis, tidak hanya ditentukan oteh kemampuan manajerial teknis para pengelola perusahaan itu. Suatu perusahaan mampu bertahan tidak hanya karena faktor-faktor teknis manajemen, bisnis, dan ekonomi. Dalam banyak kasus, suatu perusahaan bisa bertahan justru karena faktor sosialkultural. Yaitu karena kemamp Uan perUsahaan itu membangun etos bisnis atau budaya perusahaan yang baik, yang memungkinkan perusahaan itu kokoh menghadapi berbagai guncangan krisis ekonomi bisnis dan keuangan. Faktor sosial kultural di sini menyangkut kemampuan perusahaan membangun perusahaan itu menjadi sebuah komunitas yang dilkat oleh sebuah kohesi sosial budaya karena ada shared values yang dihayati bersama oleh semua karyawan dan staf manajemen perusahaan itu. Perusahaan tidak sekedar sebuah tempat mencari nafkah, melainkan sebuah keluarga, sebuah komunitas yang diikat oleh nilai bersama untuk mencapai tujuan bersama dalam sebuah solidaritas sosial yang sangat kuat.

Aspek dan nilai sosial budaya inilah yang disebut James Coleman sebagal modal sosial (social capital). Sebagaimana dikutip Fukuyama (1995), menurut James Coleman, banyak ahli ekonomi dan pelaku bisnis melupakan modal sosial ini. Yang selalu mendapat perhatian adalah pengetahuan dan ketrampilan tenaga kerja yang dianggap sebagai salah satu pilar penting keberhasilan sebuah perusahaan dan ekonomi negara. Padahal, kemampuan manusia untuk bekerja sama, uniuk menjalin sinergi strategis, den untuk saling mendukung mencapai tujuan bersama, adalah hal yang sangat penting bagi keberhasilan ekonomi sebuah negara dan keberhasilan bisnis sebuah perusahaan. Kemampuan bekerja sama ini justru dibangun dan dipertahankan d atas rangkaian nilai dan norma yang dianut dan dihayati secara bersama dalam sebuah komunitas dan sekaligus mengikat mereka dalam komunitas itu. Bagi Fukuyama, hukum, kontrak, dan rasionalitas ekonomi (dalam arti dorongan rasional untuk mengejar maksimalisasi keuntungan) merupakan dasar yang sangat diperlukan untuk mencapai kesejahteraan cian stabilitas ekonomi. Ketaatan pada hukum dan kontrak memang sangat diperfukan untuk menjamin stabilitas ekonomi dan kemakmuran suatu masyarakat. Teta pi, yang lebih penting lagi adalah hubungan timbal balik, kewajiban moral, kewajiban terhadap komunitas dan kepentingan bersama, serta saling percaya satu sama lain di antara anggota masyarakat. Fukuyama 
menegaskan bahwa keberhasilan dan stabilitas ekonomi sangat ditentukan pulaoleh dasar-dasar sosial budaya berupa nilai-nilai moral yang dihayati dan yang menjiwai pengelolaan ekonomi negara-tersebut. Bagi Fukuyama, salah satu nilai yang menjadi dasar keberhasilan ekonomi adalah saling percaya (trust). Rasa saling percaya hanya mungkin muncul of dalam komunitas yang saling mengenal, jujur, punya sikap kooperatif yang didasarkan pada nilai-nilai bersama. Rasa saling percaya inilah yang menjadi dasar dari apa yang disebut James Coleman sebagai modal sosial, yaitu karena adia saling percaya satu sama lain, karyawan bisa menjalin kerja sama yang baik, perusahaan yang satu bisa melakkukan sinergi strategis yang menguntungkan dengan perusahaan lain. Kerja sama ini terbangun karena ada komilmen pada nilai, ada ketulusan untuk saling menghargal, ada integritas moral, ada satu janji dan perbuatan, serta ada moralitas.

\section{MANAJEMEN PENGETAHUAN DAN MODAL SOSIAL DALAM PERSPEKTIF ISLAM}

Agama Islam, sebagai suatu organisasi banyak menyimpan rahasia keberhasilan dan umur panjang. Diantaranya adalah tidak hanya berorientasi pada uang. Sejarah pertumbuhan ekonomi yang balk di mana pun membutuhkan suatu aturan main yang baik dan etis. Transparansi yang dituntut oleh ekonomi global juga menuntut praktek bisnis secara etis. Dalam ekonomi global. perusahaan hanya bisa survive kalau mampu bersaing dengan pengetahuan yang tepat dan modal sosial yang memadai. Dari dua pembahasan lentang pengelolaan dan penciptaan pengetahuan yang dikemukakan Senge dengan learning organization-nya dan Nonaka dengan teori creating company-nya, ternyata keduanya tidak dapat me- ngenyampingkan masalah modal sosial yang di dalamnya terkandung nilai-nilai etika, seperti kejujuran yang akan menghasilkan trust saling percaya serta kelekatan sosial yang tinggi. Senge meletakkan etika hampir pada semua prins|p. Sedang Nonaka meletakkannya pada knowledge base, d mana unsur kebudayaan Asia Timur merupakan unsur yang penting. Budaya yang berakar dari Zen ini terkenal dengan sebutan Bushido (Pascale \& Althos, 1981), yang mencakup kebenaran, kehormatan. kesetiaan, pengendalian, kejujuran, keadilan, keberanian, kedermawanan, dan kesopanan. Demikian pula bila belajar dari nabi Muhammad dengan prinsip universal dalam bișnisnya; jujur, adil, memuaskan peianggan, tepat janji, dan kepastian hukum, hal yang seperti itu akan mendatangkan kepercayaan dari pihak manapun (Ancok, 1999). Sebagai contoh, nabi pernah memotong tangan wanita dari keluarga beliau sendiri karena korupsi. Hal ini dikuatkan oleh peneltian Gauss terhadap berbagai perusahaan yang berumur panjang. ternyata ada beberapa prinsip yang membuat umur mereka panjang, yaitu modal sosial yang banyak mengandung unsur evis dan profesionalitas.

Dalam sharing pengetahuan, nampak sekali Islam mendorong untuk terus dilakuKan. Nabi Muhammad SAW melarang seseorang menyembunyikan ilmu dengan ancaman kesengsaraan dalam kehidupan d dunia dan akhirat. Di samping itu, para sahabat beliau yang kaya selalu mendapat peringatan agar selalu memperhatikan mereka yang berada \& bawah mereka. Terutama dalam kehidupan duniawi, agar tetap bersyukur dan modal sosial mereka berkembang.

Isiam pun menekankan kehidupan yang etis, baik dalam masyarakat maupun dalam berusaha. Oleh Senge, prinsip etis dimasukkan dalam model mental. Bahkan 
muslim dituntut untuk mementingkan orang lain walaupun diri sendiri membutuhkan.

Bila dibandingkan dengan konsep Senge tentang learning organization, maka sebagaimana telah diungkapkan oleh Ancok (1999), pengendalian pribadi pun sebenarnya telah dikembangkan oleh nabi Muhammad SAW lebith dari 1400 tahun yang lału. Beliau bersabda: "Bukanlah orang yang kuat itu yang pandal dalam berkelahi, tapi orang yang kuat adalah orang yang mampu mengendalikan diri tatkala marah" (Wensinck, 1958). Datam hadist lain beliau bersabda: "Kendalikanlah dirimu". Begitu pula tatkala beliau kembalt dari salah satu peperangan yang beliau pimpin, beliau ber sabda: "Kita kembali dari jihad kecil menu/u jihad yang lebih besar; yaltu memerangi hawa nafsu".

Tentang visi bersama, nampaknya islam menjadikan sebagai suatu prinsip utama, dan menjadikannya sebagal modal sosial. Sesungguhnya orang muslim iku seperti tubuh yang satu. Mereka sangat memperhatikan kesulitan saudaranya. Apa yang dipandang baik oleh pemimpin. dipandang baik pula oleh rakyat yang paling Kecil. Nabi bersabda: "Bukankah keberhasllanmu itu karena pertolongan kaum lemahmu?"Sehingga, baik dalam atQuran maupun hadist sering dijumpal ayat maupun ucapan beliau, agar muslim selalu memperhatikan yang lemah di antara mereka. Studi Arie De Geuss yang dipaparkannya datam buku The Living Company (1997) menunjukkan bahwa hanya perusahaanperusahaan yang memiliki kepedulian sosial-etika yang berlaku universal (Payne, 1997). Mereka yang mempunyai modal sosial yang tinggilah yang mampu bertahan menerobos badai-badai krisis sehingga tetap eksis selama ratusan tahun. Di Jepang, beberapa perusahaan yang tahan banting dan berumur panjang, tenyata sangat dipengaruhi keputusan etik perusahaan yang banyak dipengaruhi nilai-nilai bushido
(Nakano, 1997). Hal ini menunizukkan bahwa pengaruh agama (Zen) masih nampak dalam manajemen modern (Achers, 1997 dan McDonald, G.M; Kan, P.C. 1997). Memang agama sendiri merupakan suatu organisasi unik yang mengandung segudang pelajaran untuk diambil hikmahnya, hingga mereka bisa berumur panjang hingga ribuan tahun. Kepedulian sosial sebagai salah satu wujud penghayatan dan pengamalan nilainilai ets itulah antara kain yang melestarikan usaha dan meriempatkan tokoh seperti Matsushita sebagai pengusaha terhormat. di mana ia menjadikan usahanya tidak hanya sekedar untuk makan (Nol For Bread Alone, 1988). Kepedulian sosial yang tinggi lah yang juga dlyakini oleh Rich Devos dan Jay Van Andel membawa bisnis mereka Amway Corporation untuk menjadi peluang Usaha yang terbaik di dunia (Collins, 1997).

Agar dapat memaksimalkan sumber daya yang mereka miliki, setiap individu muslim harus bersedia melepaskan keindividuannya. Dalam urusan penciptaan ilmu, Islam meletakkannya dalam urutan pertama. Konsep ifthad merupakan salah satu bukti perintah untuk mencipta ilmu, baik dalam urusan dunia maupun praktek keagamaan selagi tidak menyimpang dari al-Qur'an dan at hadist. Tanpa kemampuan menciptakan pengetahuan baru, produk, dan sistem ${ }_{r}$ saat ini Islam tentu sudah masuk dalam museum agama-agama. Seringnya nabi dan para khakifah melakukan dengan semua lapisan sahabat untuk berbagl pengalaman dan pengamatan dalam menghadapi berbagai situasi merupakan jalan ke arah knowledge creation, karena dalam perkembangannya, Islam yang berasal dari Arab, banyak menemukan hal-hal yang betul-betul baru dari dunia di luar Arab. Bagaimana cara mengalahkan pasukan gajah Iran yang telah memporakporandakan pasukan Islam? 
Pengetahuan tacit yang diteorikan oleh Nonaka, dalam Islam dikenal dengan nama itham. (al-Qur'an), karena ilham dipengaruhi oleh pengalaman kerja bersifat intuitif, dan ditopang oleh nilai-nilai yang melekat.

Pengalaman menunjukkan bahwa bisnis yang dibangun di atas fondasi KKN, sekalipun berhasil menjadi konglomerasi dalam sekejap mata (budaya instant), dapat lenyap dalam waktu singkat (Mittonsmith. 1997: Dean, 1997). Sejak lahirnya etika bisnis sebagai suatu ilmu baru (Vyakamam, 1996; Payne, 1997; Cohen, 1997; Dean, 1997), telah makin disadari bahwa bisnis yang baik dalam arti yang diyakni dapat berumur ratusan tahun, tidak saja harus menguntungkan (ekonomis) dan patuh hukum (legal), tetapi juga harus bermoral. Bisnis tidak lagi dapat dibebaskan dart nilainilai moral yang memandunya agar tetap baik, tumbuh dan bekembang mengikuti perkembangan masyarakat di sekitarnya.

Studi Stephen R Covey yang diuraikan lewat buku The Seven Habits of Highly Effective People (1992) juga mendukung fakta bahwa etika karakter (kehidupan organisasi yang berpusat pada prinsip) harus menjjadi fondasi bagi etika kepribadian bila perusahan ingin bertahan dalam jangka panjang.

\section{SIMPULAN}

Agar perusahaan atau organisasi dapat bertahan dan tetap survive dalam masa turbulensi ini, maka faktor pengetahuan dan modal sosial yang berkaitan dengan profesionalitas sangat perlu mendapat perhatian. Karena, bisnis yang terlalu memusatkan diri pada tujuan langka jangka pendek (cepat tumbuh dan berkembang pesat) dengan melalaikan tujuan jangka panjang (tetap bertahan selama berabad-abad) sehingga menelantarkan modal sosial, etika bisnis (kepedulian sosial), adalah bisnis yang tidak dapat diandalkan untuk membangun masyarakat, bangsa dan negara, sehingga akan cepat tumbang.

Profesionalitas adalah pedoman moral yang menuntun dan mengontrol manusia agar selalu bertanggung jawab jujur. proporsional, loyal, tegas, konsisten, komit, efisien berani, kreatif. inovatif, waspada, efektif, etis estetis, serta eftsein dalam bersikap dan betindak. Manusia harus menjadi citra profesionalnya dengan baik, karena di sanalah terletak kehormatan dan kemuliaan dirinya.

Pedoman untuk itu, ternyata sudah digariskan Islam sejak awal. Tapi ternyata sudah banyak dilupakan sehingga perlu digali lebih mendalam.

\section{DAFTAR PUSTAKA}

Achers, P. \& Preston, D. 1997. Born Again? The ethics and efficacy of the conversion excperience in contemporary manajement dev't. Journal of Management Studies, 34(5), 677.701

Ali, A.J. \& Camp, R.C. 1996. Global Managers: Qualities for Effective Competition. International Journal of Manpower. $17(6 / 7), 5 \cdot 18$.

Anand, V., Manz. C.C. \& Glick, W.H. 1998. An Organizational Mernory Approach to Information Manajement. Academy of Manajement Review, 23(4), 796-809.

Ancok, D. 1995. Revitalisasi Sumberdaya Manusia dalam Era Perubahan. Kelola, 4(8), 104-117.

1996. Managing Change Through Leadership Development Program: Social Psychological Approach. an Experience From Caltex Pacific Indonesia. Jurnal Ekonomi dan Bisnis Indonesia, 12(3), 21-30. 
1999. Manajemen Sumberdaya Manusia. Materi kullah Program Doktor Psikologi UGM (tidak diterbitkan). Yogyakarta.

2000a. Mengembangkan Kepemimpinan di Semua Lini. harian Republika, Rabu, 15 Maret, $h 13$.

2000b. Organisasi Tanpa Batas. harian Republika, Rabu, 22 Maret, $\mathrm{h} 13$.

Bought, \& C.C. Denekampt, J.G. Stevens, J.H. Osbom, R.N. 1997. Protecting Intellectual Capital In International Alliances. Journal of World Business. 32(1), 103-117

Bradaracc J. Jr. 1991. The Knowledge Link. How Firms Compete Through Strategic Alliances. Harvard Business School Press, Boston. Masaxhusetts.

Bughan, CC., Denekamp, J.G., \& Stevens, R.H. 1997. Protecting intellectual Capital in Intellectual Alliances. Journal of World Business, 32(2), 103-117, J.W.

Burton, T.T. \& Moran, J.W. 1995. The Focused Organization: Complete Organizational Alignment For Breaktrough Results. New Jersey: Prentice Hall PTR.

Chakarabarti, A.K. 1997. The Knowledge Creating Company. How Japanese Companies Create The Dynamics of Inovation, by I. Nonaka, W. Takeuchi. I EEE Transactions on Engineering Manajement. 44 (1), 99-101.

Cheng, B.S., \& Hsu, R.C. 1997. Human capital and Economic Growth in Japan. An application of time series analysis. Applied Economics Letters, 3(6). 393395.

Cohen, J.J. 1997. Learning from a master piece. Training \& Development. 51 (11)
Collins, D. 1997. The Ethical superiority and inevitability of participatory mana jement as an organizational system. Organization Science 8(5)., 489-597.

Dean, P. J. 1997. Examining the profession and practice of business ethics. Journal of business ethics. $16(15), 1638$ 1649 .

Denekampt, J.H, \& Stevens, RN, Osborn. 1997. Protecting intellectual capital in international alliances. Joumal of World Business 32:1 (Summer 1997), 103117

Dovey, K 1997. The Learning organization and The Organization of learning. Power. Transformation and The Search for formation in Learning Organization. Manajement Learning. (20 (3). 331- 349.

Draadt. J.D.R. 1997. A Sketch for human operational research in a technological society. SystemPract ice 10(4) $421-441$.

Enderle, G. A. 1997. World wide survey of business ethics in the 1990s. Journal of business Ethics 16(14) p. $1475-1483$.

Fountain, J.E. \& Atkinson, R.D. 1998. innovation, social capital, and the new economy. New Federal.

Fukuyama, 1995. Trust. The Social Virtues of the Cration of Prosperity. New York: Free Press.

Garrigou, A.G., Carballeda, G., \& Daniellou, F. 1998. The role of "know-how' in maintenance activities \& reliability in a highrisk process control plant. Applied $\mathrm{Er}_{\text {- }}$ gonomic. 29 (2). 127-131.

Hansen, M.T., Nohria N \& Tiemey, T. 1999. What's your stsrategy for managing knowledge. Harvard Business Review. March-April,. 106-116. 
Hauptman, O., \& Neuringer, J, 1997. The Knowledge Creating Company. How Japanese companies create the dynamics of inovation, by I. Nonaka, $W$. Takeuchi. Technological For ecasting \& SocialChange55 (1) 1997. P. 99-101.

Kim. W.C. \& Maubargne, R. 1997. Fair process: Managing in the knowledge of economy. Harvard Bussiness Review. July-August, 65-85.

Kotter P.J. 1998. The Leadership Factor. The Free Press. A Division of Macmilan Inc. Collier Macmillan Publisher London.

Lei, DT. 1997 . Competence building, technology fusion and competitive advantage the roles of organizational learning strategic alliances. International Journal of Technology Manajement. 14 (24). 208-237.

Levin, M. 1997. Technology transfer process as a vehicle for creating learning organization. International Journal of Technology Manajement. 14 (2-4). 297308.

Lim, B. 1995. Examining the organizational culture and organizational performance ink. A critical review of methodologies and findings of recent researchers into the presumed link between culture and performance. Leadership \& Organizathonal Development Joumal, $16(5), 16-21$.

Makhija, M. \& Ganesh, U. (1997).Information processing \& organizational learning theories to know how. Journal Organization Science. 8(5). 508-527.

McDonald, G.M., \& Kan, P.C. (1997).Ethical perceptions of expatriate and local managers in Hongkong Journal of Business Ethics, 16(15), $1605-1623$
Momillan, M.C., Baker, A.C., \& White, J. Cultural analyisis good conversation and the creation of multicultural learning organization. Manajement Learning. 28 (2). $197-215$.

Miltonsmsith, J 1997. Business ethics in Australia \& New Zealand. Journal of Business Ethics 16(14), $1485-1497$.

Nahaplet, J. \& Ghoshal, S. 1998. Social capital, intellectual capital and the ofganizational advantage, Academy Management Review, 23(2), 43-266.

Nakano, C. 1997. Business Ethics Journal of Business ethics, 1737-1751.

Nonaka, 1. \& Takeuchi, H. 1995. The Knowiedge Creating Company. How Japanese Create The Dynamic of innovation. New York-Oxford. Oxford University Press.

Ormerod. 1997. Malinya limu Ekonomi. Jakarta: Gramedia.

Pascale, Y.J. \& Althos A. G. 1981. The Art of Japanese Management, New York: Warner Book. Inc.

Payne, D, \& Raiborn, C. 1997. Global Code of Business ethics Journal of Business Erhics, $16(16), 1727-1735$.

Pulos, 5. 1997. Explicit knowledge of gravity \& the water - level task. Learning \& Individual Differences. 9 (3). 233-247.

Quinn, J.B. 1999. Strategic outsourcing: leveraging knowledge capabilities. Slaan Manajement Review. Summer 9-2t.

Rothberg, R.R. 1997. The Knowledge Creating Company. How Japanese companies create the dynamics of inovation, by I. Nonaka, W. Takeuchi. Journal of Procuct Innovation Manajement. 14 (4). 314-315. 
Sanchez, J.J., Kraus, E., White, E., \& William, M. Adopting High Involvement Human Resources Practices: The Mediating Role of Benchmarking.

Simonin, BL. 1997. The importance of collaborative know how, an empirical test of the learning organization. Academy of Manajement Journal40 (5)

Thomas, A. 1997. Organizational learning and competitive advantage. Manajement Leaming. 28 (4). 509-510.

Thomas, A.B. 1997. The coming crisis of

western change manajement. System andPractice. $10(6) .681-701$.

Tsai, W. \& Ghoshal, S. 1998. Social capital and value creation: The role of intra firm networks Academy of Management Journal, 41(4), 464-476.
Tsang, E.W.K. 1997. Organizational Learning, and the Learning Organization: A dlchotomy between descriptive \& prescreptive research. Human Relations. 50 (1). P. $73-89$.

Vanbergeijk, P.A.G, Van Hagen, G.H.A., Demooil, R.A., \& Van Jeren, J. 1997. Endogenizing technological progress. Esonomic Modelling, 14(3), 341-367.

Vyakarnam, S., Balley, A., Myers, A., \& Bumett, D. 1996. Toward an understand. ing of ethical behavior in small firms. Journal of business Ethics, $16(15)$. 1625-1636.

Zack, M.H. 1999. Managing codified knowedge. Sloan Manajement Review. Summer45-58.

Zang, $H .1997 . T$ echnology transfer, income distribution and the process $d$ economic development. Open Economic Review, 8(3), 245-270. 